\title{
ERLATIBISMOAREN EGIAK. KONSTRUKTIBISMOA, EGIA-OSTEA ETA BESTE MAMU BATZUK
}

\author{
Andoni Olariaga Azkarate \\ UEU, 261 or. \\ Bilbo, 2019
}

«Mamu bat dabil Europan zehar: erlatibismoaren mamua». Marx eta Engelsen Alderdi Komunistaren manifestuaren esaldi ospetsuaren bertsio gaurkotu horrek liburu sakon, interesgarri eta balio handiko bati ematen dio hasiera. Azken urteotan, bai gizartean bai akademian, erlatibismoaren inguruko diskurtsoa areagotu eta zabaldu egin da lau haizeetara, normalean erlatibismoa (etikoa, politikoa, kulturala...) gure garaiko gaitz handien jatorrian kokatzeko. Izan ere, gaitzen artean erlatibismoa seinalatu dutenen artean, esaterako, Ratzinger eta Bush, Badiou eta Moulines, Žižek eta Sokal pentsalari desberdin eta tradizio desberdinetakoak zerrendatu daitezke, alegia agintari politiko eskuindarrak, aita santuak eta pentsalari komunistak. Baina, ba al dago arrazoi sendorik horren kosmoikuspegi desberdinak betetzen dituzten pentsalariak ados jartzeko? Eta, ba al dago arrazoi sendorik erlatibismoari gure munduko gaitzen erantzukizuna aurpegiratzeko? Zerrenda ikusita, gure joera baiezko erantzuna ematekoa da. Hala ere, liburuaren sarreran egileak aldarrikatzen duenez, erlatibismoaren inguruko lan akademikoak geroz eta ugariagoak dira, eta horrekin batera bi fenomeno interesgarri gertatu dira: «Batetik, erlatibismoaren auziak dakartzan erronka eta inplikazioen analisiak geroz eta zorrotzagoak dira, oro har, bai alde zein kontrako argudioak formulatzen dituztenen aldetik; eta, bestetik, trataera horren ondorioz ustezko fama txar hori nolabait lausotzen ari zaio azken aldian» (20. orrialdea). Tradizio akademiko horretan kokatzen da Andoni Olariaga, bere lanaren abiapuntuari dagokionez honako hau baieztatzen duena: «Nire hipotesia da, galderaren erantzunetan sartu gabe, erlatibismoa tesi konplexu bat dela, tesi ontologiko (den-ari edo izateari buruzko), epistemiko (ezagutzari buruzko), aletiko (egia-balioei buruzko) eta moral (tradizio eta balioei buruzko) propioa duen ikuspegi konplexua dela» (21. orrialdea). Lau kapitulu luzetan zehar, Olariagak bere tesia garatzen du, era argi, aberats eta zorrotzean.

Lehenengo kapituluan («Erlatibismoaren lau auzi nagusiak. Aletika, ontologia, epistemología eta kultura»), Olariagak «erlatibismo» kontzeptu filosofikoaren lau zentzu nagusiak — legia, aletikoa, ontologikoa, epistemologikoa eta kulturala - jaso eta argitzen ditu, zentzu bakoitzean bereizten diren joera desberdinak eta planteatzen diren galdera nagusiak aztertzen dituelarik. Bide batez, epigrafe bakoitzean egilea erlatibismoaren zentzu filosofiko guztiok ikertu dituzten pentsalari eta lan nagusietara hurbiltzen da, analisi horren ondorioz erlatibismo filosofikoaren mapa orokor eta zehatza eraikitzen duelarik. Azpimagarria da Olariagak azken urteotan interes handia piztu duten hainbat gai filosofiko eta politikori ere heltzen diola, postmodernismoari 
edo egia-osteari bezala. Oso kapitulu baliagarria da, irakurleak abiapuntutzat har baitezake ondorengo kapituluetan garatzen diren gaietan errazago sartzeko.

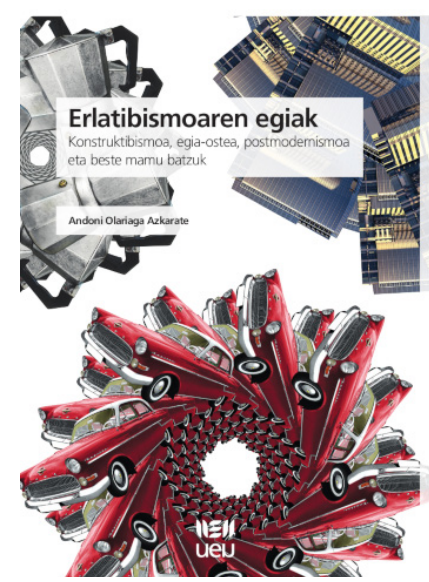

1. irudia. Erlatibismoaren egiak. Konstruktibismoa, egia-ostea eta beste mamu batzuk argitalpenaren azala.

Bigarren kapituluan («Lehen erlatibismoa. Protagoras: Gizakia da gauza guztien neurria»), Andoni Olariagak Antzinako Grezian sendotasun teoriko handiz sortu zen lehenengo erlatibismoari heltzen dio, alegia, Protagoras ordezkari nagusia duen erlatibismoari. Olariagaren interesa ez da soilik ez lehendabiziz historiografikoa; aitzitik, haren esanetan, Protagorasen erlatibismoa «interes handia izateaz gain, gaurkotasun handia daukan eta filosofiari erronka nagusiak planteatzen dizkion ideia konplexuz osatutako pentsamenduaren sistema bat da» (115. orrialdea). Iritzi hori argudiatzeari ekiten dio kapitulu osoan zehar, eta horri begira, Olariagak Grezia klasikoaren mundu-ikuskera, testuinguru politikoa deskribatzen ditu, Sokratesen eta sofistikaren arteko eztabaida filosofikoak, «gizaki» kontzeptua ulertzeko modu desberdinak eta Protagorasen erlatibismoaren zutabe nagusiak aztertzen ditu «Gizakia da gauza guztien neurria» tesi ospetsuaren analisian murgildu aurretik. Hori dela-eta, azpimarratu behar da Olariaga Joseph Margolis $(1991,1995)$ eta Ugo Zilioli (2007) akademikoen irakurketa aberatsean kokatzen dela. Nolakoa da Protagorasen erlatibismoa? Egilearen irakurketaren arabera, sofistaren erlatibismoa pertzeptuala eta indibiduoarekikoa dela baieztatzea haren pentsamendua sinplifikatzea da. Izan ere, Ziliolirekin bat etorriz, Protagorasek, batetik, erlatibismo pertzeptual sofistikatu bat proposatzen du, eta, bestetik, erlatibismo sofistikatu horrek etiko bat inplikatzen du. Bestalde, Margolisek hirugarren bektore bat gehitzen du: Protagorasen erlatibismoa ez da soilik epistemikoa, baizik eta, lehenik, ontologikoa, bigarrenik aletikoa eta, hirugarrenik, epistemikoa, hiru maila horiek barnebilduta daudelarik.

Hortik abiatuta, Andoni Olariagak Platonen Teeteto eta Kratilo elkarrizketetan deskribatzen den Protagorasen erlatibismoaren ezaugarriak —alegia, sakontasuna eta indeterminazio ontologikoa - eta tradizioan haren kontra eman diren kritikak -alegia, erlatibismoaren ustezko kontraesankortasuna, hizkuntza naturalaren 
ezintasuna eta arrazionaltasunaren oinarrizko legeen deuseztapena- aztertu eta eztabaidatzen ditu. Azterketaren ondorioz, Olariagak aldarrikatzen du Protagorasen erlatibismoa Platonen eta Aristotelesen ontologien alternatiba bat dela, eta erlatibismo subjektibista eta erlazionistaren kontra, Protagorasen erlatibismoak ontologia indeterminatu bat, erlatibismo aletiko bat eta erlatibismo pertzeptual epistemiko bat batuko lituzkeela, zeintzuen arabera munduko objektuek egitura apriorizko, unibertsal eta beharrezkoa jakin bat ez luketen, eta, indeterminismo ontologikoari lotuta, posizio aletikoan, egiaren eta gezurraren balioez haraindi, indeterminatuaren balioa ere txertatu beharko litzatekeen. Olariagak proposatzen duen interpretazio hori interpretazio tradizionala baino askoz zorrotzagoa, sofistikatuagoa eta, dudarik gabe, filosofikoki askoz aberatsagoa da.

Interpretazio berri horretatik abiatzen da, hain zuzen, Joseph Margolisen erlatibismo filosofiko indartsua. Hirugarren kapituluan («Erlatibismo garaikidearen labirintoan barrena. Metafisikaren kritika eta errealismo konstruktibista»), Andoni Olariagak Margolisen pentsamenduari heltzen dio, eta, kapituluan zehar, erlatibismo ontologiko, epistemiko eta aletiko berri bat eraikitzeko amerikar filosofoak eman dituen pausoak aztertzen ditu. Abiapuntutzat, Margolisek Aristotelesen eta Descartesen archic canon-aren (edo arkismoa-ren) - hau da, errealitateak egitura eta izaera aldaezina daukalako tesiaren- kritika egiten du. Izan ere, Margolisen esanetan: «It is not in any way conceptually necessary that reality possess invariant structures or an invariant nature» (Margolis, 1995: 24; 166. orrialdean jasoa). Izan ere, Margolisentzat, hitz egin, arrazoitu edo ezagutu ahal izateko errealitate bukatu eta egonkor bat beharrezkoa dela postulatzen duen doktrina ez da egia beharrezko bat, ezta, beste aldetik, egia-balio bibalentea aldarrikatzen duen apriorismo aristotelikoa ere. Aitzitik, arkismoaren apriorismo horien kontra, Margolisek, batetik, fluxuaren edo ordena ireki eta prekarioki egonkorraren eta, bestetik, Protagorasen errealitatearen egitura indeterminatuaren teoriak berreskuratzen ditu; hortik abiatuta, tradizio pragmatistarekin bat datorren historizitateak eta marxismoak garrantzi handia duten errea-lismo konstruktibista bat eraikitzen du. Interesgarria da seinalatzea liburuaren atal honetan, Olariagak Joxe Azurmendi filosofo euskaldunaren ikuspegi antropologikoa eta lingustikoa (gehienbat 1991 eta 2016 urteetako obretan garatua dena) Margolisen ikuspegitik gertu kokatzen dituela. Horren garrantzi intelektuala izan duen eta duen pentsalari euskaldun baten obra ikerketa honetara erakartzea ez da liburuaren bertuterik txikiena. Eta erlatibismo berriaren izaera hobeto ulertzeko, Azurmendiren obraren ondoan, Olariagak Margolisen eragile nagusiak analisatzen ditu, alegia, Hegelen historizismoa, Deweyren naturaren metafisika, Peirceren falibilismoa eta errealismo konstruktibistaren ordezkariak, besteak beste Kuhn, Searle, analitikoak, Quine eta abar. Azken epigrafeetan, Olariaga saiatzen da deskribatzen Margolisen erlatibismo indartsuaren ezaugarri nagusiak, zeintzuen artean, pluralismoaren kritika, pragmatismoaren berreraikuntza, egiabalio bibalenteen apriorismoari kritika, apriorismo aletikoaren ukazioa, errealitatea ezinbestez aldagaitza den tesiari kritika, gizakiak sozialki sortuak diren tesia eta pentsamendua historizatua delako tesia aurkitzen ditugun. Epigrafeotan Margolisek Putnam, Rorty, Davison eta beste hainbat filosoforekin garaturiko eztabaidak jasotzen dira. Kapituluaren azken epigrafean, Olariagak «XXI. mendeko 
pragmatismoarentzako erlatibismoa»ren izaeraren laburpen baliotsu bat aurkezten du.

Lehenengo hiru kapituluetan erlatibismoaren auzi nagusiak eta erlatibismoaren garapen historikoa aztertu ondoren, laugarren kapituluan («Erlatibismo erlatiboa: abiapuntu berri bat. Erlazionalismoari kritika»), Andoni Olariagak planteamendu propositibo bat egiten du, erlatibismoa zer den eta zer ez den galderei erantzun nahian. Egilearen abiapuntua Stanford entziklopediako «Relativism» artikulua da (Baghramian \& Adams, 2016). Lehenengo maila batean, Andoni Olariagak erlatibismo erlazionistaren bertsio desberdinak bildu eta kritikoki analizatzen ditu. Erlazionismoak egia, edertasuna eta ongia erreferentzia-marko batekiko egiazkoak liratekeela onartzen du; Margolisen esanetan: "There is undoubtedly an overweeming form of relativism that would replace "true" by "true in $L$ " (where " $L$ " designates disjunctively one lenguaje or another, or such context of application). This is just what we have called relationalism» (Margolis, 1991: 98; 222. orrialdean jasoa). Olariagaren iritziz, erlazionismoak eremu aletikoa eta eremu epistemikoa batzen ditu, arazo teoriko sakonak sortzen dituena, besteak beste paradoxa autorreferentziala, inkonsistentzia logikoa eta interes eza. Bestalde, erlazionismoak mailatan (ontologia, epistemología eta aletikan) eta eremutan (kognitiboa, morala eta abarretan) fragmentatzen du erlatibismoa. Olariagaren iritziz, berriz, litekeena da erlatibismo ez erlazionista bat garatzea. Izan ere, horren arabera bi erlatibismo mota bereizi daitezke: erlazionista, auzi aletikoa auzi epistemikoari lotzen diona, eta ez erlazionista edo erlatibismo propio bat, auzi aletikoa beregain aztertzen duena. Erlatibismoaren bertsio guztiak analisatu ondoren, Olariagak bere bertsio propioa proposatzen du. Proposamen horrek erlatibismo irekiago bat aurkezten digu, non hiru tesi aurki genitzakeen: 1) Erlatibismo aletikoa. Egiaren izaeraren ikuspegi indeterminatua luke, eta egiaren muga klasikoen ezinbestekotasun eza. Alegia, tertium non datur eta hirugarren baztertuaren printzipioak ez direla aldarrikatuko luke, eta egia-balio aniztasunak (ahulagoak) daudela defendatu, egia-balio bibalenteen beharrezkotasunaren aurka. 2) Erlatibismo logikoa. Bertsio indartsuenean (Priest, 2004), kontraesan logikoen onarpena, kontraesanak hizkuntzan eta logikan oro har emango liratekeela aldarrikatuko luke, eta kontraesanen egiatasuna eta faltsutasuna aldi berean aldarrikatzeak ez lukeela arrazionaltasunaren ukoa ekarriko, alegia, konsistentea litzatekeela defendatuko luke. 3) Erlatibismo ontologikoa. Indeterminazio-ontologia edo ontologia historizatua aldarrikatuko luke; alegia, posible dela errealitatean gauza bat eta bere kontrakoa izatea (Priest, 2004, 2016), eta errealitatearen izaera eta egitura indeterminatu gabea izatea (Margolis, 1991), errealitatea eta pentsamendua produktu indeterminatu eta historikoak direlako (Azurmendi, 1999).

Laugarren kapitulua amaitu ondoren, Olariagak erlatibismo filosofikoaren defentsa labur batekin amaitzen du liburua. Bestalde, lanak bibliografia zabal bat eskaintzen du (249-258 orrialdeak), baita Index baliotsu bat ere. Laburbilduz, liburu sakon, erudito, interesgarri eta balio handiko baten aurrean gaude. Eskergarria da, beraz, UEUk etorkizunari begira erlatibismo filosofikoaren inguruko lanaren jarraipena bultzatu lezakeen Andoni Olariagaren liburu baliotsua argitaratu izana. 


\section{Aipaturiko erreferentzia bibliografikoak}

Joxe Azurmendi, J. (1991): Gizaberearen bakeak eta gerrak, Elkar, Donostia.

, (1999): Euskal Herria krisian, Elkar, Donostia.

, (2016): Gizabere kooperatiboaz, Jakin, Donostia.

Baghramian, Maria eta Carter, J. Adam, (2016): «Relativism», The Stanford Encyclopedia of Philosophy, Edward N. Zalta (ed.), URL $=<$ https://plato.stanford.edu/archives/ win2019/entries/relativism/>.

Margolis, J. (1991): The truth about Relativism, Basil Blackwell, Oxford.

-, (1995): Historied thought, construed world. A conceptual primer for the Turn of the Millennium, University of California Press, Berkeley, Los Angeles, Kalifornia.

Priest, G. (2004): «What's So Bad About Contradictions?», in Graham Priest, J.C. Beall \& Bradley Armour-Garb (edit.), The Law of Non-Contradiction. New Philosophycal Essays, Clarendon Press, Oxford, 23-38.

, (2016): «Torn by Reason: Lukasiewicz on the Priciple of Contradiction», Early Analitic Philosophy-New Perspectives on the Tradition, Springer, 80. bol., 429445.

Zilioli, U. (2007): Protagoras and the Challenge of relativism. Plato's subtlest enemy, Ashgate Hampshire, Ingalaterra.

Javier Aguirre Santos 
